\title{
Effective Home Automation Using Android and Embedded System
}

\author{
Asmaa Y. M. Hashem ${ }^{1}$, Fawzy A. Osman ${ }^{2}$, Mostafa A. R. Eltokhy ${ }^{1,}$ Ail S. Gab Allah ${ }^{3}$ \\ ${ }^{1}$ Electronics Technology Department, Faculty of Industrial Education, Helwan University, \\ Cairo, Egypt \\ ${ }^{2}$ Electrical Engineering Department, Faculty of Engineering, Banha University, Cairo, Egypt \\ Curricula, teaching methods and educational technology Department, Faculty of Education, \\ Benha University, Cairo,Egypt \\ m_yusuf7@yahoo.com,fawzi.osman@bhit.bu.edu.eg,mostafaeltokhy2717@yahoo.com. \\ alyzzz2000@gmail.com
}

\begin{abstract}
:
The home automation needs to make use of latest and advance technology to makes it flexible, reliable and cost effective. Home automation involves introducing a degree of computerized or automatic control to certain electrical and electronics system in a building. The popularity of home automation has been increasing greatly in recent years due to much higher affordability and simplicity through smartphone and tablet connectivity. Most research aims to design and develop home automation system which is wireless and can be controlled via a multiple way to give more accessibility and control over a wide range of the systems. The main purpose is to develop and design an automation system which is accessible remotely to monitor and controlling it in a user-friendly way. Wireless communication in home automation systems is focused on low-power wireless communication modules. This paper proposes a costeffective home automation system which is contains a combination of Android smart phone or tablet or a laptop and embedded system which include Arduino Due Board, Ethernet Shield module and Relay circuit. Also, most researches use an open source or a payed software to be used under Android media of the smart phones, but here the required interface Android pages are designed and implemented by researcher which reduce the cost of the proposed system effectively.

Key words: Home Automation System, Arduino Due, Android software programming, Ethernet Shield module.
\end{abstract}




\section{Introduction}

Many methods are used for controlling home appliances, where the use the mobile as a remote control was introduced in [1] and the use of text SMS is presented for controlling In $[1,2]$. Home automation using wireless device becomes popular and several wireless devices are available like Bluetooth, Zigbee and GSM. Many mobile phones have a built-in Bluetooth and its use with Home automation application is introduced in [3]. Also, ZigBee was introduced as another solution of a wireless devices for use with Home automation application as in [4] where, the performance of ZigBee based sensor network for patient monitoring through simulations carried out using ns2.35 simulator tool. A system based on the LabVIEW software is used to monitor and control the home equipment's and can act as a security guard of the home is presented in [5]. The system also has internet connection to monitor and control the house equipment's from anywhere in the world. A low cost and flexible home control and environmental monitoring system is presents in [6] which employs an embedded micro - web server in Arduino Mega 2560 microcontroller, with IP connectivity for accessing and controlling devices and appliances remotely. These devices can be controlled through a web application or via Bluetooth Android based Smart phone applications. As flexible and an inexpensive home control and monitoring system, a network system based on Raspberry $\mathrm{Pi}$ and using Arduino Microcontroller was discussed in [7-10]. The interface between the Access Point and switches with IP connectivity for accessing devices and appliances and controlling it remotely will be made by using Android based Smartphone application or server computer. ESP8266 has been used as a gateway or the main server in the whole system [11], which has various sensor connected to it via wired or wireless communication. A flexible standalone, low cost smart home system, which is based on the Android application communicating with the micro-web server providing more than the switching functionalities [12-16]. The Arduino Ethernet is used to eliminate the use of a personal computer (PC) keeping the cost of the overall system to a minimum. An Internet of Things (IoT) based prototype of a smart home automation is designed and implemented [17-20] for smart home system along with its Android App and ATmega16 or ESP8266 computer network module and Arduino Uno as its main controller is successfully presented.

\section{Required Software programs:}

A number of different programming tools were used to design our home automation system; Arduino IDE, Android Studio, Genymotion (Android emulator), Geany.

\section{Arduino IDE}

Arduino is an open-source platform used for building electronics projects. Arduino consists of both a physical programmable circuit board (often referred to as a microcontroller) and a piece of software, or IDE (Integrated Development Environment) that runs on your computer, used to write and upload computer code to the physical board. Arduino boards are able to read inputs from a variety of 
switches or sensors, making Decisions, and controlling a variety of outputs such as lights, motors, motion and temperature. In our proposed system Arduino Due Kit is used.

\section{Android Studio}

Android is an open source and Linux-based operating system for mobile devices such as smartphones and tablet computers which provides the fastest tools for building apps on every type of Android device. Android offers a unified approach to application development for mobile devices which means developers need only develop for Android, and their applications should be able to run on different devices powered by Android. Android programming is based on Java programming language and the Android Studio (version 2.3) is used here in our paper, you can download it from android developer web.

\section{Genymotion (Android emulator)}

Genymotion is an Android emulator based on Virtual Box and is the most popular fast \& easy android Emulator. It can emulate specific devices and allows you to install/run/test apps on it, which makes it great for you to use it on a daily basis or just to test your apps (for developers). Since Virtual Box is cross-platform compatible, Genymotion will work on Windows, Mac and Linux too.

\section{Geany}

Geany is a small and lightweight Integrated Development Environment. It was developed to provide a small and fast IDE, which has only a few dependencies from other packages. Another goal was to be as independent as possible from a special Desktop Environment like KDE or GNOME - Geany only requires the GTK2 runtime libraries. Geany is known to run under Linux, FreeBSD, NetBSD, OpenBSD, MacOS X, AIX v5.3, Solaris Express and Windows.

\section{Required Hard-Ware}

\section{Ethernet Shield}

The Arduino Ethernet Shield allows you to easily connect your Arduino to the internet. This shield enables your Arduino to send and receive data from anywhere in the world with an internet connection. This shield opens up endless amounts of possibility by allowing you to connect your project to the internet in no-time flat. Arduino Ethernet Shield provides internet connection through Ethernet. This board which is based on Wiz net W5100 IC is compatible with both TCP and UCP. There is a SD card socket on board. Therefore, you can write various information to or read them from SD card. SD card can be used with SD Library. Arduino, communicates with Wiz net 5100 which is the processor of Ethernet Shield and SD card through SPI line. Those pins are 11, 12 and 13 on UNO and 50, 51 and 52 on MEGA and Due. The shield must be assigned a MAC address and a fixed IP address using the Ethernet. Begin() function. A MAC address is a globally unique identifier for a particular device. 


\section{Channel Relay Board}

This module contains 8 relays, rated at $5 \mathrm{~V}$ and $10 \mathrm{~A}$. Each relay has a LED indicator. It can be used to control various appliances, and other equipment with large current. It can be controlled directly with $3.3 \mathrm{~V}$ or $5 \mathrm{~V}$ logic signals from a microcontroller. Each relay has an optocoupler, providing optical isolation. Each relay also has a freewheeling diode protection. Each relay has an Optocoupler, providing optical isolation. Each relay also has a freewheeling diode protection. This module has a 6-pin header (standard $2.54 \mathrm{~mm}$ pitch) for connecting power (5V and GND), and controlling the 8 relays.

\section{Other components such as;}

- DTH11 Sensor

- Power supply $(5 \mathrm{v}, 12 \mathrm{v})$

- Power Bank for Arduino

- Router

- Ethernet cable

\section{Application pages Designed Using Android Studio}

We used Android Studio (version 2.3) to design our application that help us to monitor and control our home automation system that is interfaced with a server via Ethernet.

\section{Our application consists of five Layout activities: -}

1. Login Activity, consists of two Edit Texts (e-mail and password) and two Button (Login and Register).

2. Register Activity, consists of three Edit Texts (e-mail, password and confirm password), one Button (Register) and one Text View (Back to Login).

3. Server Activity, is defined as Web View which means that the Server Activity will load URL and open it, where URL is considered as IP address for Web Server that is programed by HTML program. Consists of Float Action Button, If, the user enters on it, it will open $\mathrm{p} 2 \mathrm{p}$-wificam app to open the camera that help the user to monitor the whole system.

4. Db Helper Activity, which is considered as a temporary storing data activity (e-mail and password) and is responsible for sending the data (e-mail and password) from register activity and transferring it to session activity.

5. Session Activity, which is responsible for receiving the data (e-mail and password) and saving it by using SQL Database.

\section{Application Flow Chart}

This application is designed to work as home automation control system that allow the operator to monitor and control all things that can be interfaced with a server via Ethernet. This application consists of five Layout activities (Login, Register, server 
activity, dB Helper and Session activity) which flow charts are given in Fig. 1 through 4. Note: Server activity contains float action button. If the user pushed, it will open P2PCamer app to open the camera that help the user to monitor the whole system.

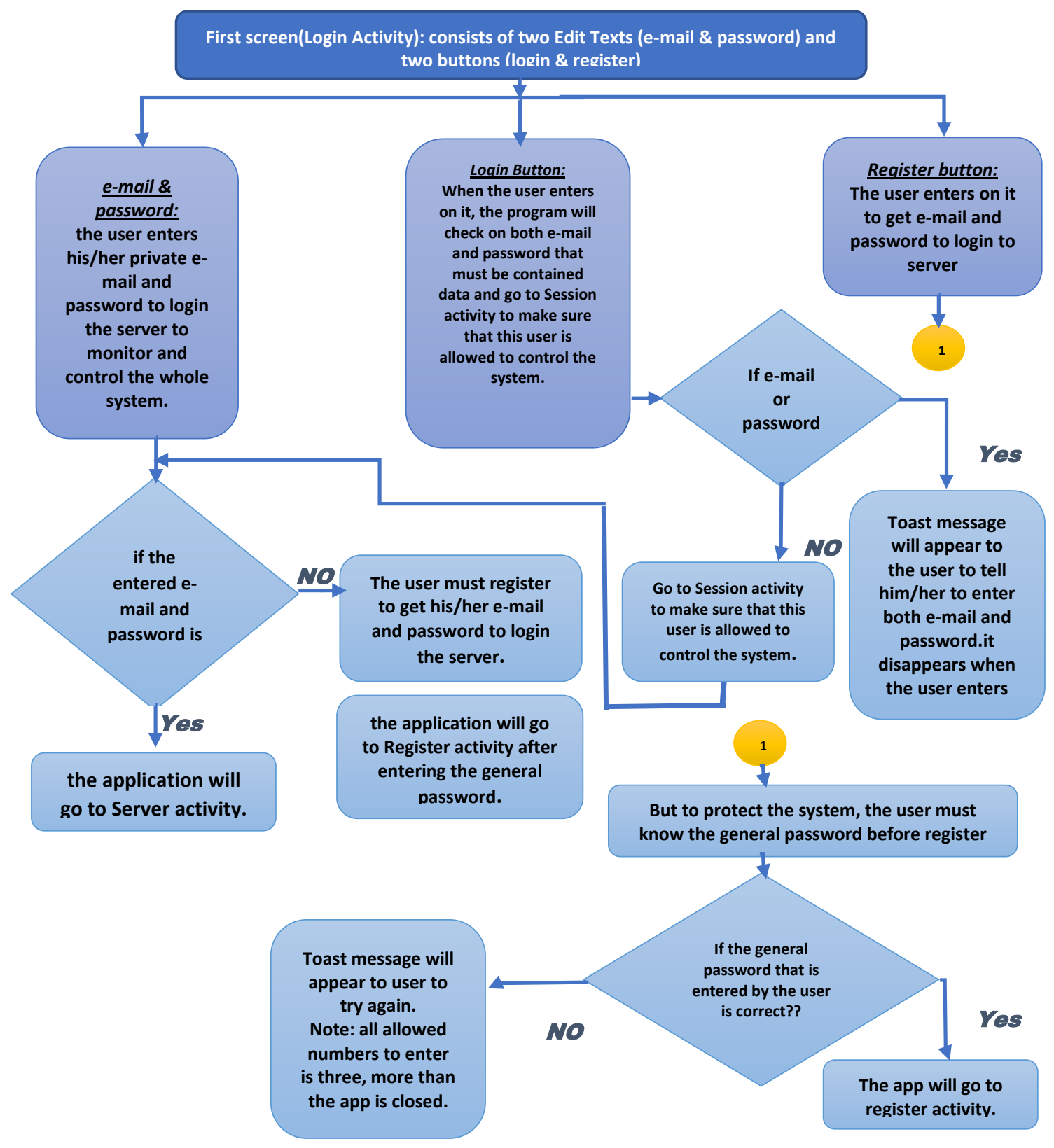

Fig. 1 Complete flow chart for Login Activity 


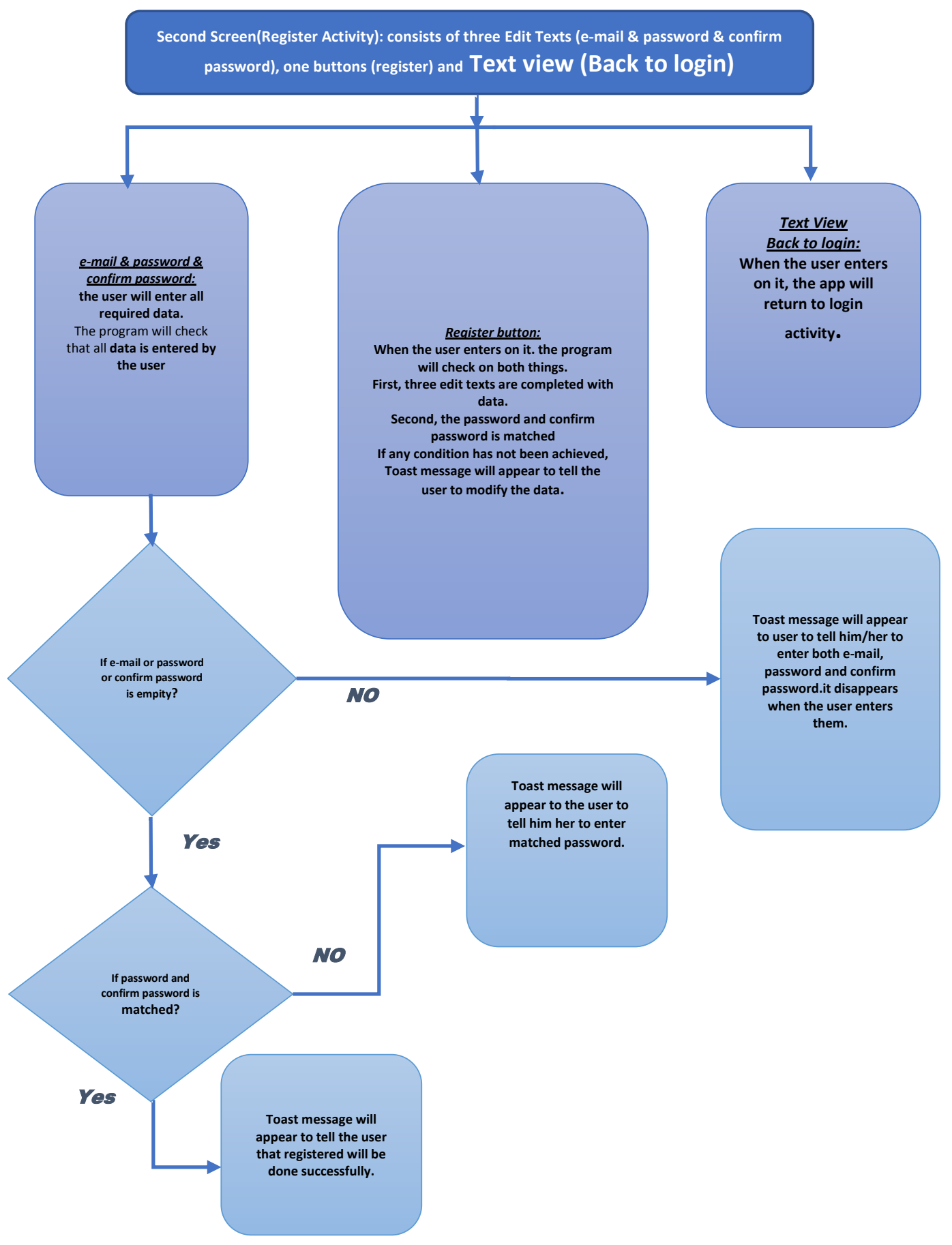

Fig. 2 Complete flow chart for Register Activity 


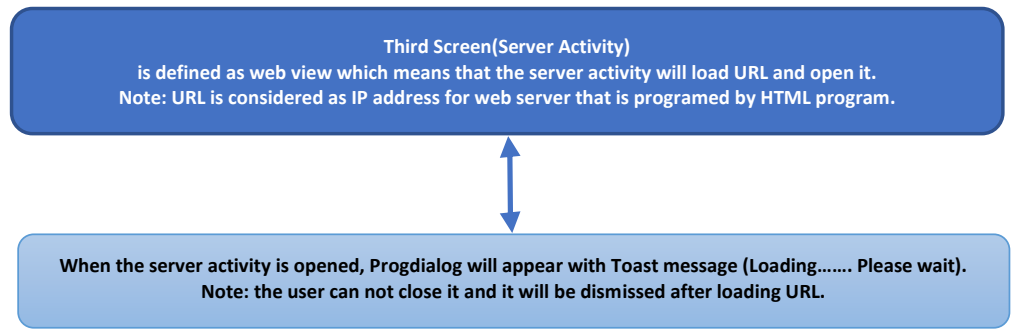

Fig. 3 Complete flow chart for Server Activity

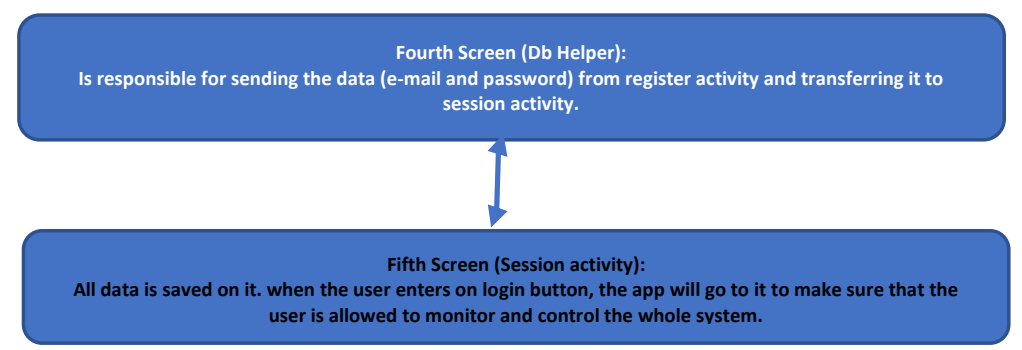

Fig. 4 Complete flow chart for DB-Helper Activity

\section{Proposed Program}

\section{Screen Shots of the proposed Application in Android Studio Program}

Android programming is based on Java programming language and the Android Studio (version 2.3) is used here in our paper, you can download it from android developer web. Screen shots for some pages of the application activities are givens as follows in Fig. 4 through 8.

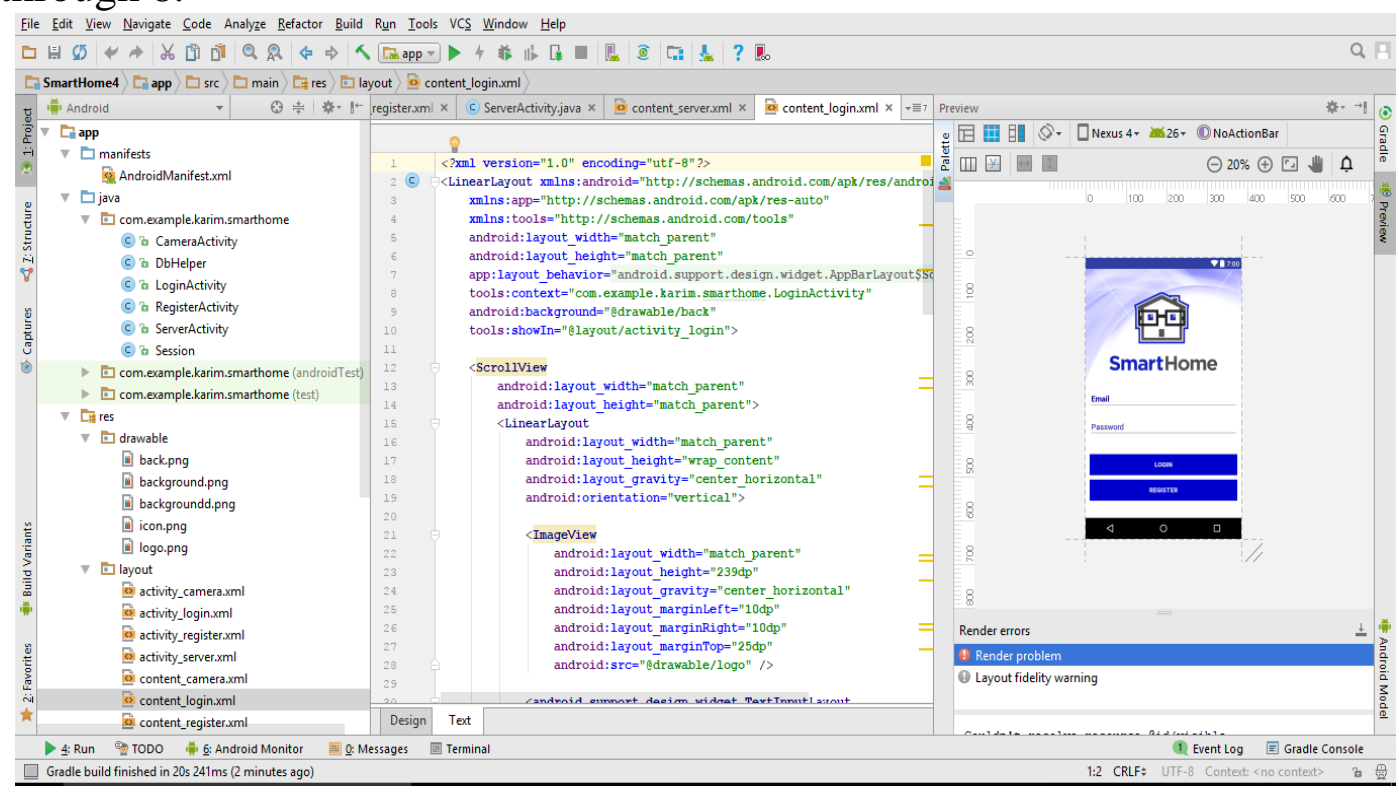




\section{Fig. 5 Login Activity in Android app.}

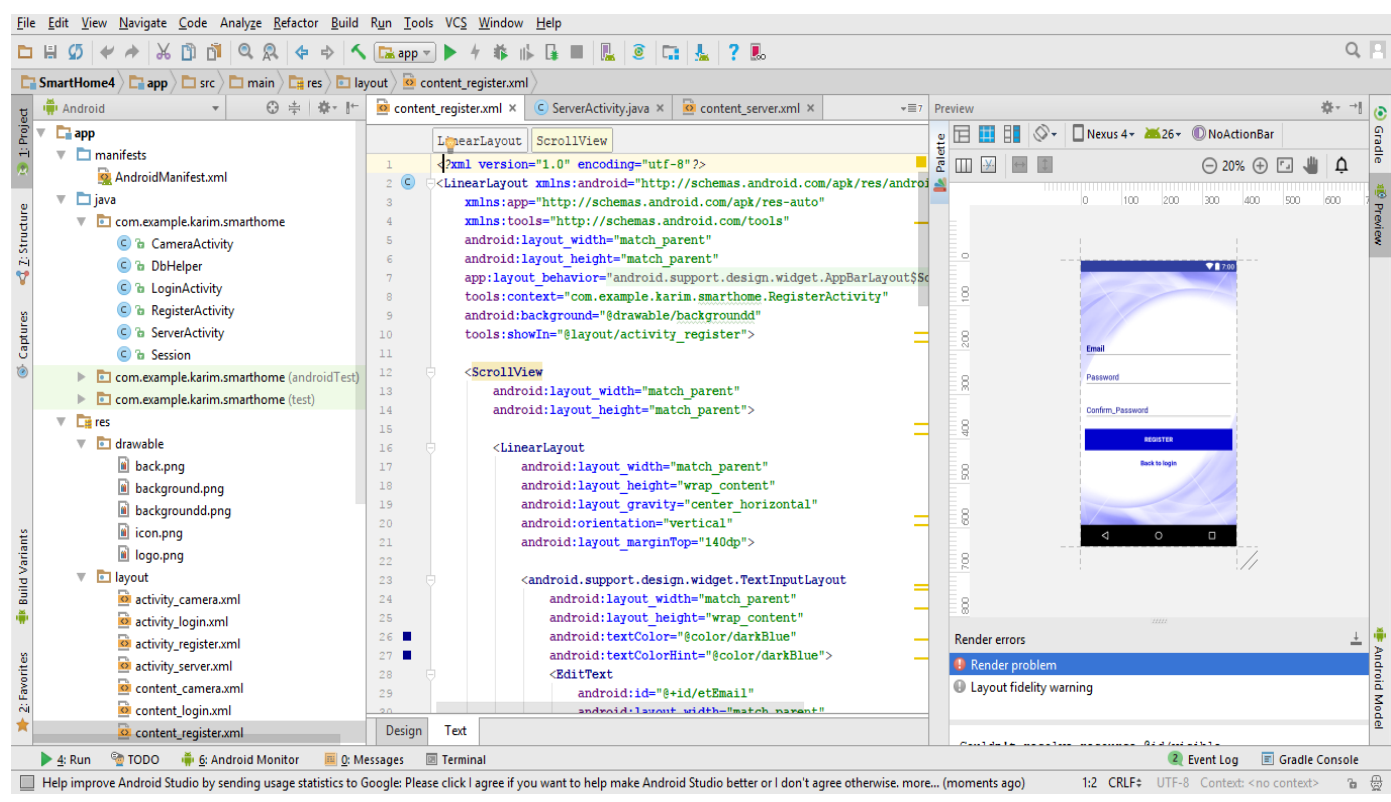

Fig. 6 Register Activity in Android app.

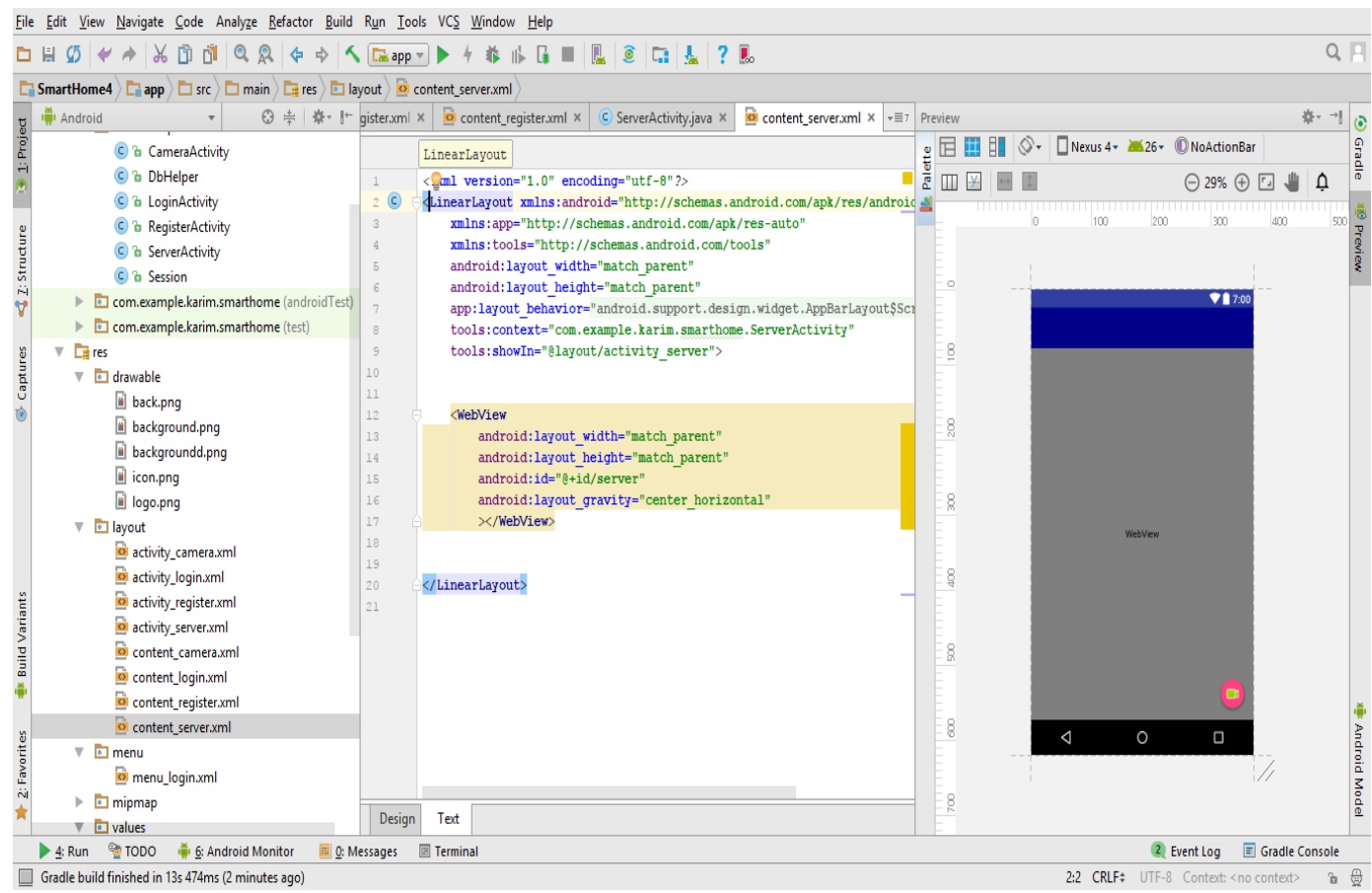

Fig. 7 Server Activity in Android app. 


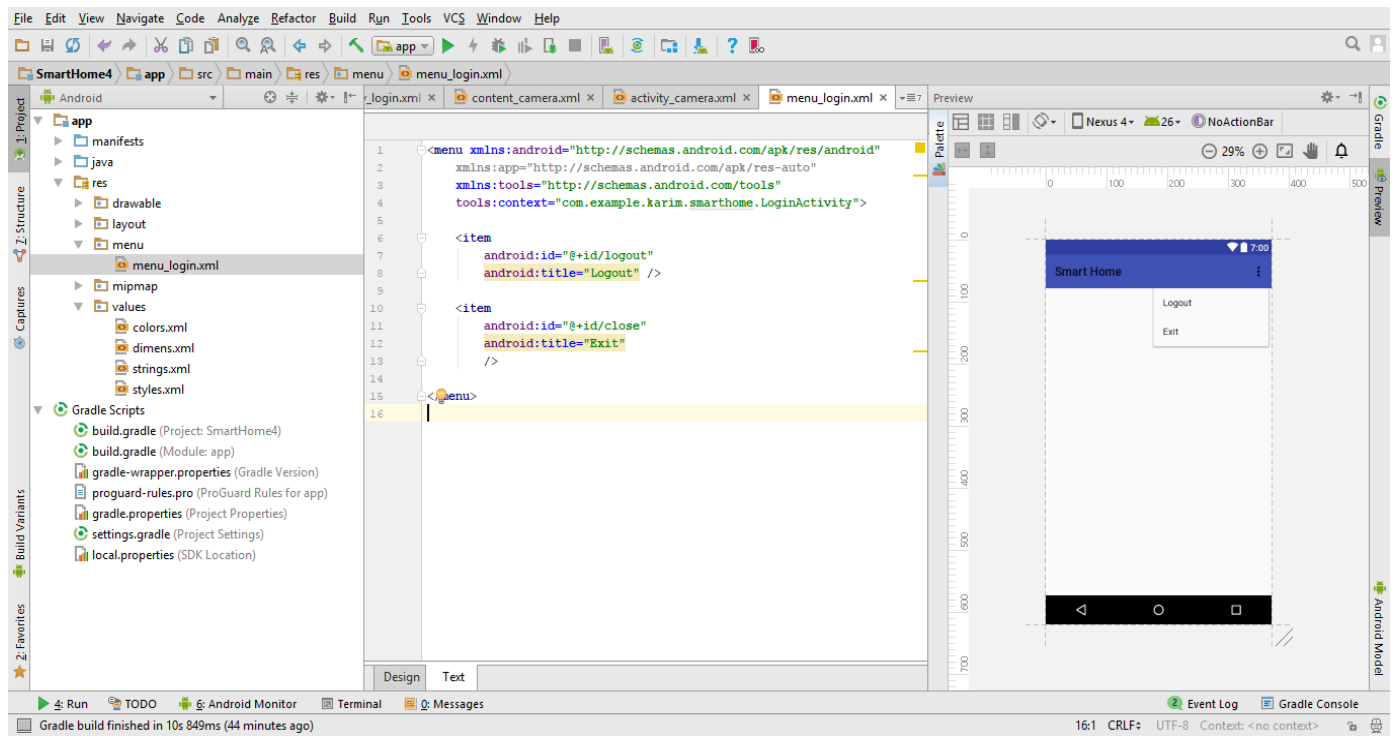

Fig. 8 Menu in Android app. 

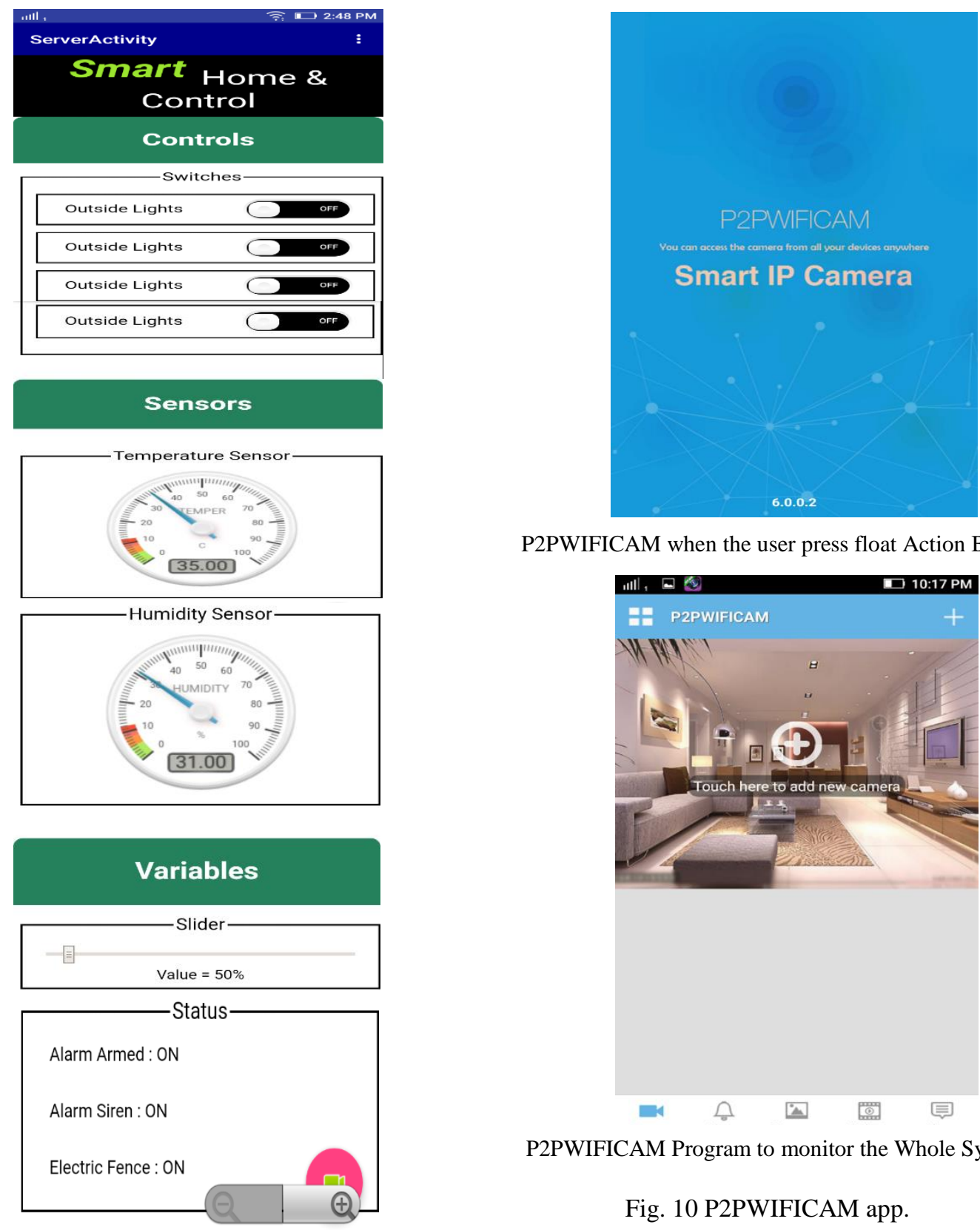

P2PWIFICAM when the user press float Action Button

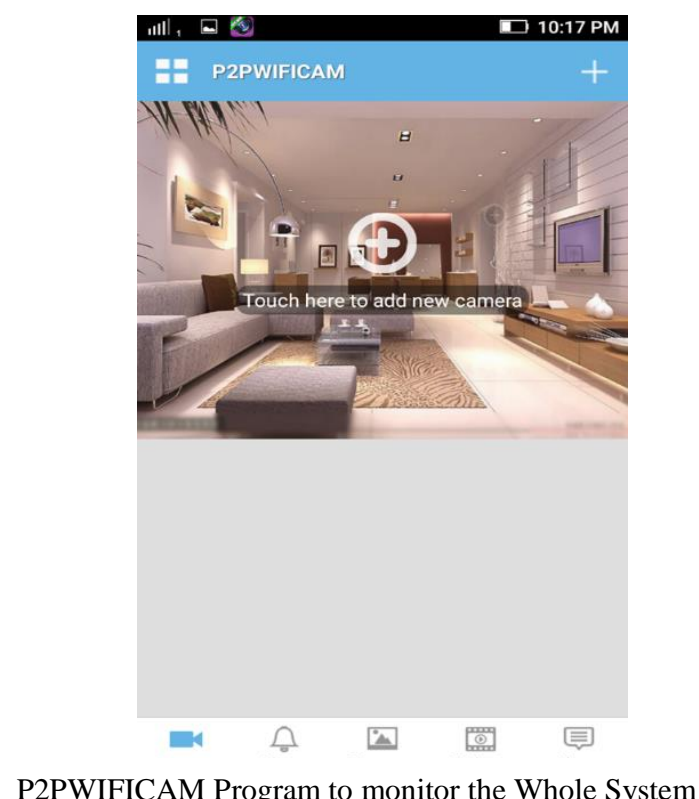

Fig. 10 P2PWIFICAM app.

Fig. 9 Web server in Android app.

Fig. 9 show the complete view for the proposed program under the Android application devices, which used to control and monitor some lights and Fans that run at the utility power supply $220 \mathrm{vAC} 50 \mathrm{~Hz}$. Also monitor the values of Temperature and Humidity at the predefined area of the house. It also contains an analog slider which change the 
value of the PWM output signal as a percentage value to be used to control different DC loads such as a LED lighting or a brushed DC motor to varies its speed. The status of different loads and alarm status are indicted at the bottom of the page. Fig. 10 indicate the operation of the P2PWIFICAM when the specified button is pressed and its window for monitoring the specified area to be covered.

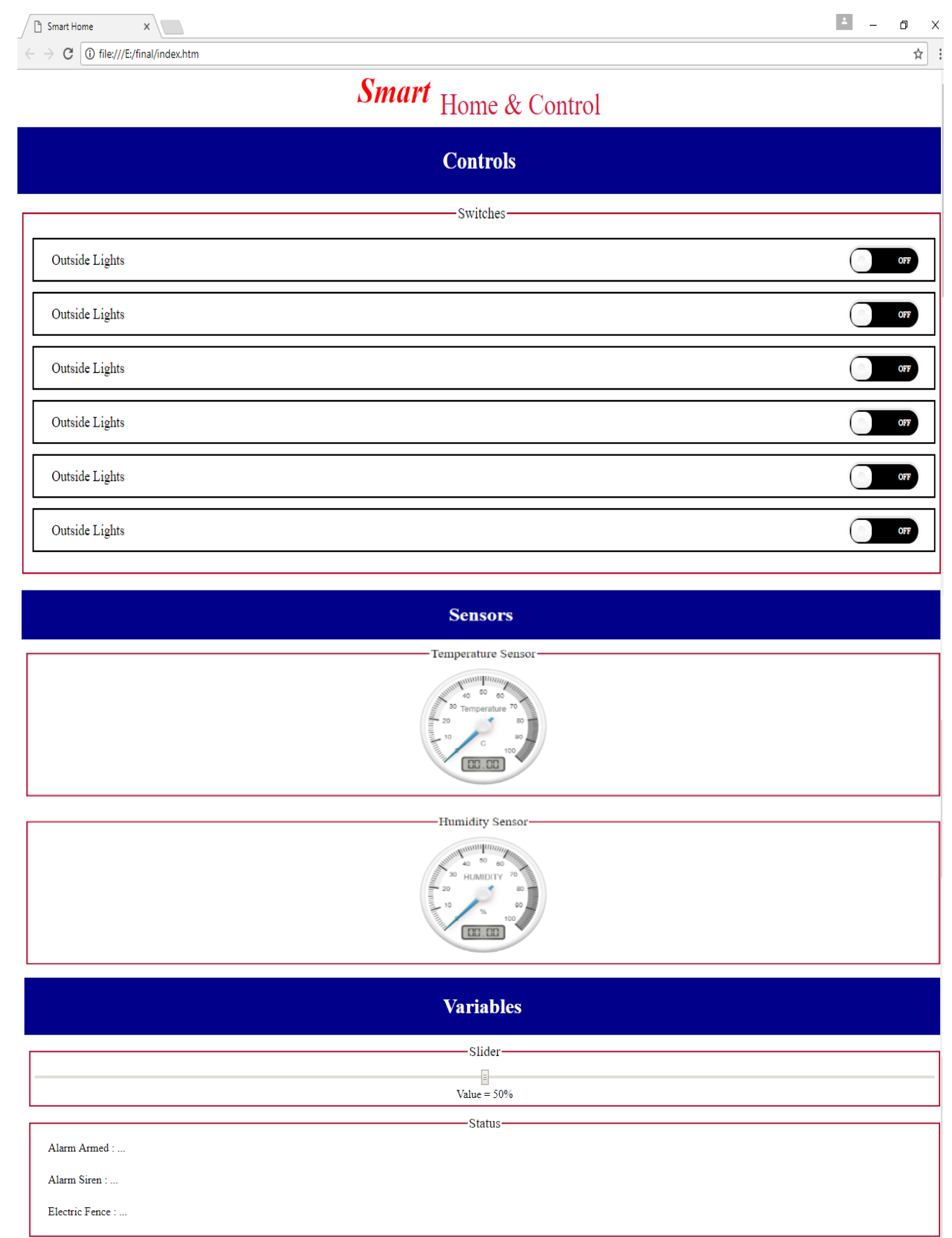

Fig. 11 Web Server 
Fig. 11 show the proposed program under HTML programming to be operated using Laptop or PC which have all the component to be controlled or monitored as in Android application devices.

\section{Experimental Hardware}

\section{- Control on DC load}

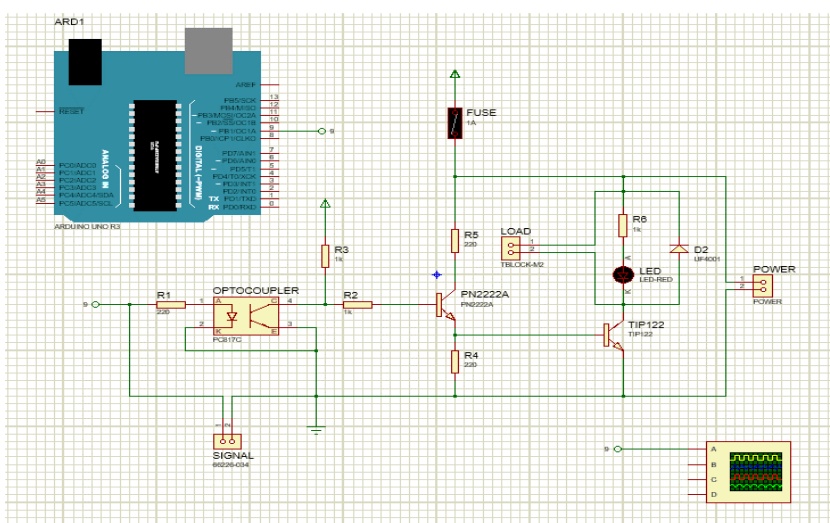

Fig. 12 Schematic Circuit for control on Dc

The output PWM signal from the Arduino DUE board are isolated using optocoupler PCB17C and then derived to the DC motor using Darlington transistor TIB122 which provide it with the required load current.

\section{- Phase Angle Control}

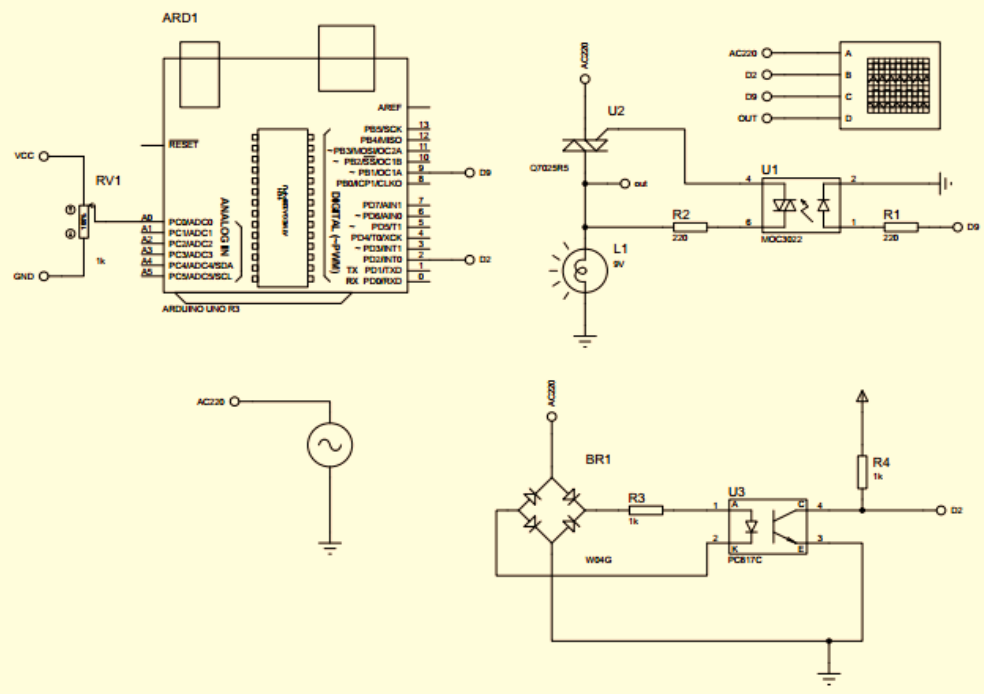

Fig. 13 Schematic Circuit for Phase Angle Control

Here a phase angle control circuit which use a bridge and an optocoupler to a zerocrossing signal from the main source and send it to the $\mathrm{MC}$, hence the firing angle delay is introduced using a VAR resistance connected to an analog channel of the DUE 
board. The control signal fed to an optical isolated TRIAC, MOC3022, which drive a power TRIAC to control the AC loads.

\section{- Main Connection Board}

Purpose: Cable Management and connection between microcontroller and actuators. Fig. 14 and Fig. 15 shows the schematic and the hardware circuit for the Main Connection Board, MCB. Fig. 16 show the complete wired system which contains an Arduino DUE Board with the Ethernet shield and the driving AC and DC boards and the Main board.

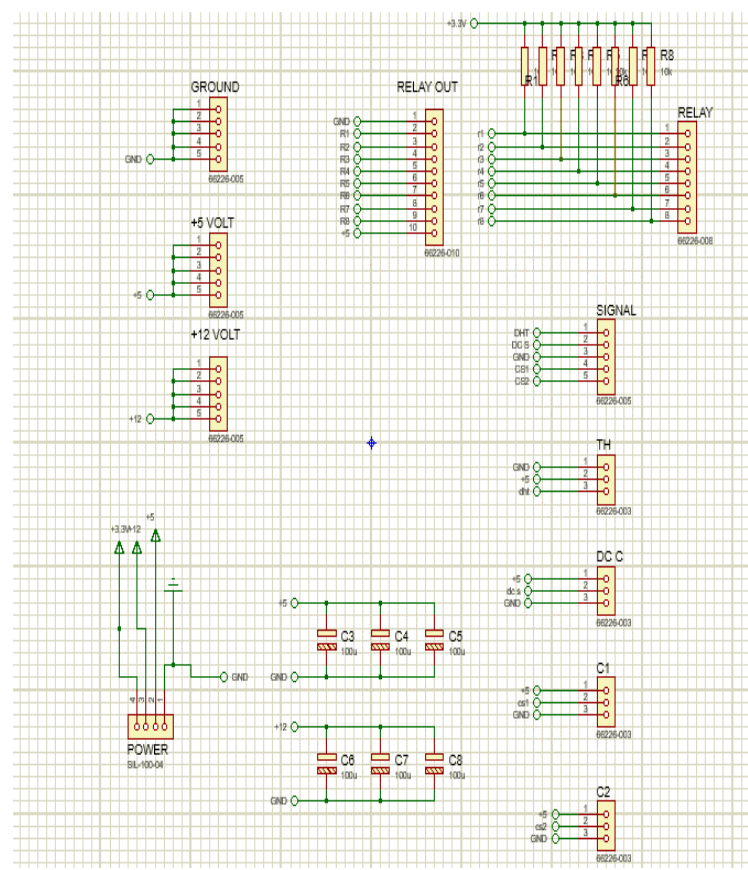

Fig. 14 Schematic Circuit for Main Connection Board

\section{Conclusion}

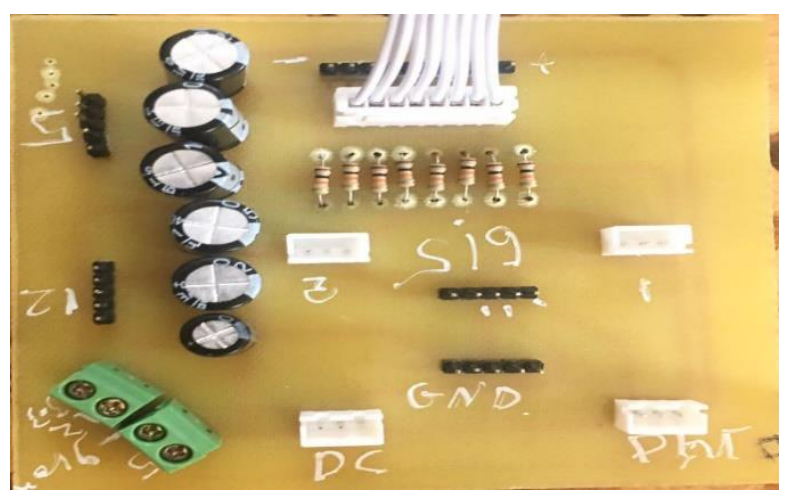

Fig. 15 Hardware Circuit for Main connection board

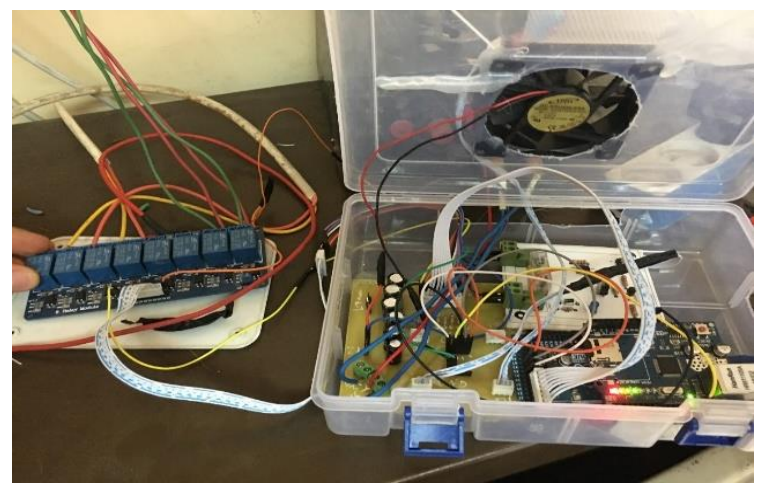

Fig. 16 Final Hardware Circuit for the complete system

This paper proposes a cost-effective home automation system which is contains a combination of Android smart phone or tablet or a laptop and embedded system which include Arduino Due Board, Ethernet Shield module and Relay circuit. Also, most researches use an open source or a payed software to be used under Android media of the smart phones, but here the required interface Android pages are designed and implemented by researcher which reduce the cost of the proposed system effectively. Android programming is based on Java programming language and the Android Studio (version 2.3) is used here in our paper. Also, the program task was carried out using HTML programming to be operated under Windows via a Laptop or a PC. The 
proposed program under the Android application devices, which used to control and monitor some lights and Fans loads that run at the utility power supply 220 VAC 50 Hz. Also monitor the values of Temperature and Humidity at the predefined area of the house. It also contains an analog slider which change the value of the PWM output signal as a percentage value to be used to control different DC loads such as a LED lighting or a brushed DC motor to varies its speed. The status of different loads and alarm status are indicted at the program page. The operation of the P2PWIFICAM achieved when the specified button is pressed and its window for monitoring the specified area to be covered are indicated.

\section{References:}

1. F. Baig, S. Beg, "Controlling Home Appliances Remotely through Voice Command", International Journal of Computer Applications (0975 - 888) Volume 48- No.17, June 2012.

2. P. B. Patil, R.R. Patil, S.V.Patil, "Home Automation System Using Android and Arduino Board”, International Journal of Innovative Research in Science, Engineering and Technology Vol. 5, Issue 4, April 2016.

3. A. K. Singh, S. Balamurugan and K. Aroul, "Home Automation S Using Bluetooth-A Review", Journal of Engineering and Applied Sciences VOL. 11, NO. 21, NOVEMBER 2016.

4. S. A. Nagar1, S. Bhatnagar, "ZigBee on Wireless Sensor Network for patient monitoring and Home Automation Application", International Journal of Scientific Research \& Engineering Trends Volume 5, Issue 1, Jan-Feb-2019.

5. B. Hamed, "Design \& Implementation of Smart House Control Using LabVIEW", International Journal of Soft Computing and Engineering Volume-1, Issue-6, January 2012.

6. N. David, A. Chima, "Design of a Home Automation System Using Arduino", International Journal of Scientific \& Engineering Research, Volume 6, Issue 6, June-2015.

7. H. H. Hadwan, Y. P. Reddy, "Smart Home Control by using Raspberry Pi \& Arduino UNO", International Journal of Advanced Research in Computer and Communication Engineering Vol. 5, Issue 4, April 2016.

8. M. Milosevic, N. Cetic, J. Kovacevic, T. Andelic, "Lighting Control Using Raspberry Pi and Oblo Living Home Automation System", Serbian journal of electrical engineering, Vol. 16, No. 1, February 2019.

9. C. Bepery, S. Baral, A. Khashkel \& F. Hossain, "Advanced Home Automation System using Raspberry-PI and Arduino”, International Journal of Computer Science and Engineering Vol. 8, Issue 2, Feb - Mar 2019.

10. J. Dorve, M. K. Samarth, S. R. Jais "A Review on Home Automation using Voice Via Bluetooth Through Raspberry PI 3", International Journal of Research in Engineering, Science and ManagementVolume-2, Issue-3, March-2019.

11.S. Balakrishnan, B. Madhurekha, N. Shobana, "Home Automation System using ESP8266 based MQTT", International Journal of Research in Engineering, Science and Management. Volume-2, Issue-2, February-2019.

12. S. Anwaarullah, S.V. Altaf, "RTOS based Home Automation System using Android", International Journal of Advanced Trends in Computer Science and Engineering, Vol.2, (2013). 
13. S. Kumar, "UBIQUITOUS Smart Home System Using Android Application”, International Journal of Computer Networks \& Communications (IJCNC) Vol.6, No.1, January 2014.

14. M. A. Mowad, A. Fathy, "Smart Home Automated Control System Using Android Application and Microcontroller", International Journal of Scientific \& Engineering Research, Volume 5, Issue 5, May-2014.

15. S. M.Patel, S.J. Pasha, "Home Automation System (HAS) using Android for Mobile Phone", International Journal of scientific Engineering and Technology Research July-2015.

16. N. Baidya, P. Kumar, "A Review Paper on Home Automation", International Journal of Engineering and Techniques - Volume 4 Issue 1, Jan - Feb 2018.

17. T. A. Abdulrahman, O. H. Isiwekpeni, "Design, Specification and Implementation of a Distributed Home Automation System", International Workshop on Internet of Things, Networking Applications and Technologies, 2016.

18. K. Charumathi, H.H. Shareen, R.Sushmitha, R.Suriya, K.Prasanna, "Controlling and Monitoring of Smart Home Appliances using IOT", International Journal of Trendy research in Engineering and Technology, Volume 2, Issue 2, April 2018.

19. K. K. Rout, S. Mallick, S. Mishra, "Design and Implementation of an Internet of Things Based Prototype for Smart Home Automation System”, Conference Paper, July 2018.

20. R. Wankhade, S. Karhade, P. Mohite, "Home Automation System Based on IOT using Cellular Devices”, Themed Section: Science and Technology Volume 6, Issue 2019. 